\title{
On the estimation of nose velocities and their influence on the physical habitat simulation for Barbus Bocagei
}

\author{
F. Martínez-Capel ${ }^{(1)}$, D. García de Jalón ${ }^{(2)}$, M. Rodilla-Alamá ${ }^{(1)}$
}

Corresponding author: F. Martínez-Capel, fmcapel@dihma.upv.es

\begin{abstract}
Although more explicit habitat simulation models for calculating instream habitat are being developed, current applications of PHABSIM for instream flow assessments are based on average velocities. This article focuses on the behavior of Barbus bocagei (a species native to the Iberian Peninsula) in terms of focal (nose) height and velocities. In a four-year research project, we first surveyed habitat use in four rivers (by underwater observation) and developed site-specific and generalized habitat suitability criteria (category II) for focal velocity and focal height (distance from bed). Second, we calculated focal velocities from the average in four different ways and computed the consequent errors to compare the models' precision in the 4 study sites. Third, as a practical approach, habitat criteria for focal velocities were introduced in a selected example, to measure the changes affecting W.U.A./flow functions. We discuss the problems in implementation and the general consequences for instream flow studies.
\end{abstract}

Key words. - nose velocities, habitat simulation, suitability criteria, Phabsim, instream flow

\section{INTRODUCTION}

In the research dedicated to improve physical habitat simulation, for IFIM (Bovee 1982) and other purposes, more explicit models have been developed, and they can combine precise topographic, hydraulic and biological data to obtain reliable results. In the one hand, biological studies are providing more and better information, because there are different techniques available. In particular, underwater surveys can provide a 3 dimensional view of the fish behavior, at least when we work with species inhabiting clear waters. In the other hand, many applications are based on 1 or 2 dimensional hydraulic models which simulate average velocities, and 3 dimensional model can make a better profit of specific biolog-

(1) Dpto. Ingeniería Hidráulica y Medio Ambiente. Universidad Politécnica de Valencia. Campus de Vera s/n. 46022, Valencia, SPAIN.

(2) E.T.S. Ingenieros de Montes. Universidad Politécnica de Madrid. Madrid 28040. SPAIN. 
ical information, like the microhabitat preferences in terms of focal (nose) velocity, focal height, use of undercut banks, etc.

There are situations when more reliable results could be obtained if the calculations are based in the exact position of the fish in the water column (Milhous 1999). One example is the physical habitat simulation for epi-bentic fishes, like Barbus sp., that feed and swim very near to the bottom. Several species endemic to the Iberian Peninsula also spawn on the bottom of the stream, especially in gravel beds, like Chondrostoma sp. and the same Barbus sp. One can also think about study sites with coarse substrate or deep pools, where fish can find an important shelter in flood periods, like occurring in the Mediterranean hydrological regimes (Prenda 1993; GranadoLorencio 1996).

The data used here come from a four-year research project (supported by the Spanish authorities for Science and Technology), in which we studied the habitat criteria for 3 cyprinids, which are native to the Iberian Peninsula, in 9 sites of the Tagus ba$\sin$ (Central Spain). For this article we have selected only 4 reaches, based on their habitat heterogeneity and the sample size for one species: Barbus bocagei. Our objectives in this article are:

- To describe Barbus behavior in terms of its position in the water column, and to analyze its relationships with other microhabitat variables.
- To observe the errors obtained when focal (nose) velocities are modeled in different ways and reaches of different hydraulic characteristics.

- To assess the practicability and consequences of the implementation of these data for a physical habitat simulation.

\section{METHODS}

\section{Study Sites and Sampling}

The study reaches were all located in basins under Mediterranean conditions, characterized by the intermittence with periods of torrential rain and drought, and a high intra-annual and inter-annual variation in stream flow. These variations are decreasing due to the high number of large dams and hydropower plants functioning in Spain (see García de Jalón 1987; Martínez-Capel et al. 2000; Baeza et al. 2001). The 9 sites (in 7 rivers) all belong to the Tagus Basin and were selected following these criteria: underwater visibility, habitat heterogeneity, species abundance and minimum influence from human activities.

Barbus was present in the nine sites, but here we have selected only four, due to their habitat heterogeneity and a minimum number of microhabitat records (25): river Ambroz, Guadiela, Jarama and Sorbe. They have in common well forested basins, and the stream banks were vegetated with trees and shrubs. There are no large 
urban developments along the rivers upstream the sites. The fish assemblages are very similar: cyprinids are the dominant species (MartínezCapel \& García de Jalón 1999; Martínez-Capel 2000).

Before field surveys, Barbus bocagei were divided into 3 size classes for all the analysis, i.e., $<70 \mathrm{~mm}, 70-220 \mathrm{~mm}$ and $>220 \mathrm{~mm}$, based on previous works (LobónCerviá \& Fernández Delgado 1984; Doadrio et al. 1991; García de Jalón et al. 1997; Martínez-Capel \& García de Jalón 1999). We followed the procedure described by Li (1988) and Heggenes (1991) to get habitat use data by underwater observation. Upon sighting a fish or shoal of them, the observer estimated the size class and counted the number of fish of each class. The diver recorded the data on a dive slate: number of the point marker, species, fish number, size class and focal height (distance from the stream bed) estimated in percentage (except when fish was very near to the bottom, so few centimeters could be estimated). When a fish or shoal was disturbed by the diver, or showed fleeing behavior, it was not recorded. All data were collected during daylight hours. When the snorkeling was completed, microhabitat information was recorded at each fish location: water depth, mean water column velocity, focal (nose) point velocity, distance to the nearest shore (nearest $10 \mathrm{~cm}$ ), dominant substrate type within a 0 ' $15 \mathrm{~m}$ radius of the fish and cover type. Both velocities, average and fo- cal, were recorded by the same person at the same point.

Water depths were recorded with a graduated rod (nearest $\mathrm{cm}$ ), so focal height was calculated in situ to allow us the focal velocity measurement. A Valeport ${ }^{\circledR}$ electromagnetic current meter was used to measure velocity (nearest $\mathrm{mm}$ ). When water depth was higher than a meter, instead of the measurement at $0.6 \times$ depth, the average at $20 \%$ and $80 \%$ of the water depth was used.

Substrate categories considered were: Bedrock, large boulders (> $1024 \mathrm{~mm})$, boulders (256$1024 \mathrm{~mm})$, cobbles $(64-256 \mathrm{~mm})$, gravel (8-64 mm), fine gravel (2$8 \mathrm{~mm})$, sand $(62 \mu \mathrm{m}-2 \mathrm{~mm})$, and silt $(<62 \mu \mathrm{m})$. We matched theses classes with their average size in $\mathrm{mm}$ to compute the D65 in every site (i.e., $65 \%$ of the stream bed is covered by sediments smaller than the D65).

After the microhabitat data were collected, habitat available in each site was sampled following transects perpendicular to the stream flow. They were randomly positioned, in each habitat type, so that we could record the available variability in terms of depth, velocity, substrate and cover. At classifying habitat types we followed the criteria defined for the Basinwide Visual Estimation Technique -BVET- (Hankin and Reeves 1988; Dolloff et al.1993). To characterize the study sites in physical terms, we also determined the minimum monthly average flow and mean annual flow (both based on at least 10 years of records) in $\mathrm{m}^{3} / \mathrm{s}$; total wa- 
ter surface in the site $\left(\mathrm{m}^{2}\right)$; water surface gradient in $\mathrm{m} / \mathrm{km}$ (measured with an optical level); central $50 \%$ of the data distribution for depth $(\mathrm{m})$ and velocity $\left(\mathrm{m}^{3} / \mathrm{s}\right)$, and the coefficient D65 $(\mathrm{mm})$ of the bottom substrate (i.e., $65 \%$ of the samples have a substrate with diameters minor than D65).

\section{Habitat Suitability Criteria and Fish Position}

The first part of this work consisted of the description of the fish behavior, in terms of some microhabitat variables. First of all we put all the data together (from the four reaches) and looked at the depth, focal height (distance from bed), average velocity and focal velocity for each size class. Habitat use by Barbus, in the 4 reaches, has been described through the central intervals that can be called suitable and optimal (following Thomas and Bovee 1993), i.e., the central $95 \%$ and $50 \%$ of the data distribution. Those intervals define the habitat suitability criteria (category II data, Bovee 1986) for the three life stages. Here we have presented these data, which we consider useful for PHABSIM applications in Iberian rivers, and also some "box and whiskers" plots for the comparison between size classes. In some cases we have checked statistical differences between groups through the KruskalWallis and the median tests. It was also analyzed the correlation between depth and percentage of focal height, in order to see if the position in the water column was independent and specific for a species and size class.

\section{Estimation of focal velocities}

To go for the second objective of this article, we began checking the correlation between focal velocity and average velocity. We first used a power regression, which was applied to all the data (the 4 reaches) together. After this general approach, we studied every reach separately.

In every reach we tried four different models to compute focal velocity from the average at the same point, following similar ideas to the exposed by Milhous (1999). The first model was the empirical solution based on the power law of velocity distribution, with this simple form:

\section{Fvel $=$ Avel $\times\left\{a(F h / D)^{b}\right\}$}

Where the symbols correspond to:

Fvel: focal velocity $(\mathrm{m} / \mathrm{s})$ at the fish position,

Avel: average velocity $(\mathrm{m} / \mathrm{s})$ in the water column at the fish position,

Fh: focal height $(m)$, i.e., vertical distance from stream bed to fish position,

$\mathrm{D}$ : depth $(\mathrm{m})$ at the fish position, $a, b$ : coefficients obtained by regression analysis.

In order to find this empirical solution, we computed a potential regression between the ratio $\mathrm{Fvel} / \mathrm{Avel}$ and $\mathrm{Fh} / \mathrm{D}$, so we had 4 parameters at each point. For this and the following analysis, we discarded a $15 \%$ of the extreme data, in order to obtain a better fit to all the models. Therefore, here 
we used the actual (measured) focal height and velocity at each point, so the consequent errors were evaluated in every different focal height, and not for an average.

For all the models, the error in every record was estimated as the difference between simulated and measured focal velocity divided by the measured focal velocity (\%).

The second model was similar to the former, but we calculated the empirical solution with a fixed focal height: the average focal height for the 3 size classes, computed in every reach independently. Then we only had 3 parameters in the analysis. This case also differs to the former in the meaning of the errors obtained, because for every measurement the actual focal velocity was compared with the one that was modelled at a different focal height (the average for the particular reach). From this point of view we expected higher errors, but we think that, for a habitat simulation, it would be practical to apply this sort of models for a specific focal height of a target species. In the other three models, errors were evaluated in all the range of the variable, which will be noted in each case.

The third model was based on the power law equation (Schlichting 1968), in the following form (see Milhous 1999):

$$
\text { Fvel }=\text { Avel } \cdot\left\{(m+1)(F h / D)^{m}\right\}
$$

Where the symbols are the same mentioned before; and $\mathrm{m}$ is a coefficient obtained for every reach. This $\boldsymbol{m}$ can be a constant (for example
Schlichting estimated 1/7) and also can be computed by different equations. By fixing the four parameters in every measurement (with focal height variable), $m$ was calculated to satisfy the equation. For this model we used the average $\mathrm{m}$ calculated in every reach.

We also want to mention that we tried to fit $\boldsymbol{m}$, in every reach, with this equation:

$$
m=a(D / D 65)^{b}
$$

Where the symbols correspond to:

$\mathrm{D}$ : depth $(\mathrm{m})$ at the fish position, D65: substrate diameter $(m)$ that satisfy the condition that $65 \%$ of the stream bed is covered by sediments smaller than the D65. In this equation D65 is taken as the characteristic roughness height in the reach.

$a, b$ : coefficients obtained by regression analysis.

In the four reaches the correlation was so poor that we decided to discard this analysis for the present work.

The fourth (last) model for the test was a different transformation of the former (Milhous 1999):

\section{Fvel $=$ Avel $\cdot\{\log (33.2 \mathrm{Fh} / \mathrm{D} 65) /$ $\log (12.12 \mathrm{D} / \mathrm{D} 65)\}$}

Where the symbols are the same mentioned before. In this equation D65 is also taken as the characteristic roughness height in the reach.

After the four models were tested, we counted the number of points with errors included in few intervals. Then we calculated the frequency of errors in those intervals: error $<10 \%, 10$ - 
$25 \%, 26-50 \%, 51-75 \%, 76-100 \%$ and $>100 \%$. To compare the 4 models (for the four reaches together and separately), we used the KruskalWallis test that compared the medians of the groups. In order to select a best model, we considered the maximum percentage of data with errors in the interval of $0-25 \%$, and the percentage of data in the other intervals.

We were also wondering if the errors could be a function of the physical characteristics of the sites, i.e., the variables used to characterize the available habitat. For this purpose, we plotted the errors against the water surface gradient, hydraulic radius (average for the transects in the reach), percentiles 50 and 95 of depth and velocity and percentile 50 of substrate diameter. We also tried to find trends of the errors with the continuous microhabitat variables: average velocity in the same point of measurement, focal velocity, focal height and depth. Only the relevant results have been explained in the results section.

\section{Physical Habitat Simulation}

Our last objective was to assess the consequences of this different approach for a physical habitat simulation. First we selected a reach with several microhabitats and a complete survey for the hydraulic simulation through RHYHABSIM (Jowett 1989). We calculated depths and velocities in every point of the transects, so we got the hydraulic data for ten different flows and the calibration flow. One model was selected for the calculation of focal velocity from the average. Based on the hydraulic results we calculated weighted usable area for large barbels (using MS Excel ${ }^{\circledR}$ ), by introducing two habitat criteria: total depth with average velocity and focal height with focal velocity.

Here we have considered interesting to remark that, if the calculated optimal and suitable focal heights are lower than the minimum depth suitable for the fish, it would not be necessary to introduce focal height criteria in the simulation. This is because when suitable depths were available, there would be a wide range of focal heights suitable for the fish. In another situation, habitat criteria for focal heights should be introduced in the WUA calculations, independently from depth habitat criteria.

For a better comparison, we have used only depth and velocity (we did not consider substrate, nor cover). Both habitat suitability criteria (category II) have been calculated from the same reaches and the same individuals. As we proceed exactly the same for computing WUA in both ways, we controlled the calculations without the use of any specific program and used exactly the same area, depth and velocity for each cell, and the same combined suitability (geometric median of the two suitability values). 


\section{RESULTS}

\section{Study Sites and Sampling}

For the site characterization, at different scales, we selected some relevant variables, in terms of habitat and hydraulics (Table 1).

Sorbe and Guadiela were the largest reaches, in terms of surface (measured in the days of survey) and they had high habitat heterogeneity, due to the physical structure of the stream bed and the presence of some large boulders, little islands, vegetation, caves, etc. Ambroz and Jarama were smaller reaches, with some good refuges but less habitat complexity.

\section{Habitat Suitability Criteria and Fish Position}

In order to illustrate the habitat use by Barbus, we calculated the $50 \%$ and $95 \%$ central range of the data distribution, and the results are shown in Table 2, where sample size is indicated for each size class. The corresponding medians for the three size classes are not included in the table.

Table 1. - Variables selected to characterize study sites at different scales.

\begin{tabular}{|c|c|c|c|c|c|c|c|}
\hline $\begin{array}{c}\text { Site } \\
\text { Code }^{*}\end{array}$ & $\begin{array}{c}\text { MMAF }_{\mathrm{a}} \\
\& \mathrm{MAF}_{\mathrm{b}} \\
\left(\mathrm{m}^{3} / \mathrm{s}\right)\end{array}$ & $\begin{array}{c}\text { Tot. } \\
\text { surface } \\
\left(\mathrm{m}^{2}\right)\end{array}$ & $\begin{array}{c}\text { Habitat } \\
\text { units } \\
\text { sequence }\end{array}$ & $\begin{array}{c}\text { W.S. } \\
\text { gradient } \\
(\mathrm{m} / \mathrm{km})_{\mathrm{d}}\end{array}$ & $\begin{array}{c}\text { Depth } \\
\text { central } \\
\text { range }_{\mathrm{e}}\end{array}$ & $\begin{array}{c}\text { Velocity } \\
\text { central } \\
\text { range }_{\mathrm{e}}\end{array}$ & $\begin{array}{c}\text { Stream } \\
\text { bed } \\
\text { D65 }_{\mathrm{f}}\end{array}$ \\
\hline Ambroz & $0.32 / 3.76$ & 665 & $\mathrm{P}$ & 0.46 & $0.27-0.88$ & $0.017-0.154$ & 0.16 \\
\hline Guadiela & $1.99 / 5.04$ & 3721 & $\mathrm{R}, \mathrm{P}, \mathrm{R}$ & 3.38 & $0.50-1.12$ & $0.017-0.116$ & 0.036 \\
\hline Jarama & $2.17 / 5.03$ & 1229 & $\mathrm{P}, \mathrm{R}, \mathrm{P}, \mathrm{R}$ & 1.67 & $0.11-0.26$ & $0.010-0.020$ & 0.16 \\
\hline Sorbe & $0.50 / 2.62$ & 3794 & $\mathrm{P}, \mathrm{Ra}, \mathrm{P}, \mathrm{R}, \mathrm{P}, \mathrm{P}$ & 5.80 & $0.15-0.69$ & $0.045-0.325$ & 0.64 \\
\hline
\end{tabular}

${ }^{a}$ Minimum Monthly Average Flow (based on at least 10 years of records) in $\mathrm{m}^{3} / \mathrm{s}$

${ }^{b}$ Mean Anual Flow (based on at least 10 years of records) in $\mathrm{m}^{3} / \mathrm{s}$

${ }^{\circ}$ Sequence of habitat units in the site. P: Pool, R: Riffle, Ra: Rapid.

${ }^{d}$ Water Surface Gradient in $\mathrm{m} / \mathrm{km}$.

${ }^{e}$ Central $50 \%$ of the data distribution (interquartile range), depth in $\mathrm{m}$ and velocity in $\mathrm{m} / \mathrm{s}$.

${ }^{\mathrm{t}}$ Coefficient D65 for substrate diameter, in $\mathrm{mm}$.

Table 2. - Summary of the habitat suitability criteria (habitat use data) recorded for Barbus bocagei in the 4 reaches of the Tagus basin.

\begin{tabular}{|c|c|c|c|c|c|c|}
\hline Size-class & $\begin{array}{c}\text { Central } \\
\text { Range }\end{array}$ & Depth $(\mathrm{m})$ & $\begin{array}{c}\text { Focal Height } \\
(\mathrm{m})\end{array}$ & $\begin{array}{c}\text { Focal } \\
\text { Height } \%_{1}\end{array}$ & $\begin{array}{c}\text { Average } \\
\text { Velocity }(\mathrm{m} / \mathrm{s})\end{array}$ & $\begin{array}{c}\text { Focal Velocity } \\
(\mathrm{m} / \mathrm{s})\end{array}$ \\
\hline Large & $95 \%$ & $0.6-2.23$ & $0.02-0.46$ & $2-40$ & $0.01-0.541$ & $0.005-0.215$ \\
\hline $\mathrm{N}=81$ & $50 \%$ & $1.09-1.52$ & $0.03-0.20$ & $3-17$ & $0.069-0.194$ & $0.032-0.097$ \\
\hline Medium & $95 \%$ & $0.22-1.90$ & $0.02-0.52$ & $2-50$ & $0.005-0.465$ & $0.008-0.301$ \\
\hline $\mathrm{N}=150$ & $50 \%$ & $0.36-1.14$ & $0.03-0.10$ & $4-20$ & $0.064-0.189$ & $0.026-0.118$ \\
\hline Small & $95 \%$ & $0.15-1.03$ & $0.02-0.15$ & $2-40$ & $0.008-0.216$ & $0.006-0.180$ \\
\hline $\mathrm{N}=18$ & $50 \%$ & $0.32-0.68$ & $0.03-0.08$ & $4-23$ & $0.019-0.094$ & $0.015-0.097$ \\
\hline
\end{tabular}

${ }^{1}$ Focal height is the vertical distance from the stream bed to the fish position, and the percentage is calculated in relation to total depth at each point. 
The specific results for large barbels, noted in Table 2 and Table 5, have been selected for the physical habitat simulation, as indicated in the fourth part of the Results.

When focal height was considered in absolute terms (in $\mathrm{m}$ ), clear differences (Kruskal-Wallis $p<0.01$; median test $p<0.05$ ) arose between size classes (see Figure 1). For this variable, the median of large fishes $(0.10 \mathrm{~m})$ was higher that the median for medium and small ones (both $0.05 \mathrm{~m})$. However, when the data

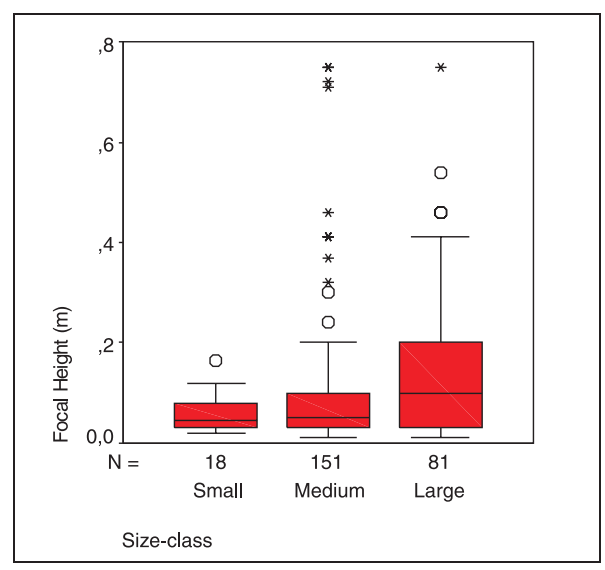

Figure 1. - Comparison of focal height (in $\mathrm{m}$ ) between the three size classes of Barbus bocagei, through box and whiskers plots ${ }^{(3)}$.

(3) The box encloses the interquartile range, i.e. the middle 50 percent (the median is represented as an horizontal line inside). The lower whisker indicates the smallest point within 1.5 interquartile ranges from the lower quartile, and the other whisker indicates the largest point within 1.5 interquartile ranges from the upper quartile. Circles mean far values that fall within 3 interquartile ranges (suspect outliers) from the lower or upper quartile, and asterisks are further outside points (outliers). were compared in terms of percentage of focal height, fish behavior looked really similar for the 3 size classes, what is confirmed by the statistical tests (Kruskal-Wallis $p=0.15$; median test $\mathrm{p}=0.46$ ).

Barbus bocagei mainly feed on the benthos, detritus and vegetation in the bottom (Valladolid y Przybylski 1996) and its dependence of substrate is clear when this last analysis is done, because the median of focal height percentage is between $8-12 \%$ in all cases. In the underwater surveys, we have observed how the swimming capabilities of the medium and large individuals allow them to move in different water conditions, while small ones must stay feeding on the stream bed. This observation is consistent with the results for focal velocity, because the median is higher for medium $(0.064 \mathrm{~m} / \mathrm{s})$ and large fishes $(0.059 \mathrm{~m} / \mathrm{s})$ than the small ones $(0.023 \mathrm{~m} / \mathrm{s})$. However, for this variable we have not found a significant difference (Kruskal-Wallis $p=0.22$; median test $p=0.30$ ).

In regards to depth, clear differences show that Barbus occupy deeper microhabitats as it becomes larger (see Figure 2). This observation is consistent with other cyprinids and has been statistically demonstrated (Kruskal-Wallis and median test $p<0.01$ ).

We also wondered if there was a relationship between depth and the position in the water column. For this purpose we have computed a potential regression. Global results (gathering the 3 size classes, $r^{2}=0.15$, 
$\mathrm{N}=150$ ) reveal a trend to stay closer to the stream bed as the depth increases (Figure 3).

When size classes were treated separately, we observed that this be-

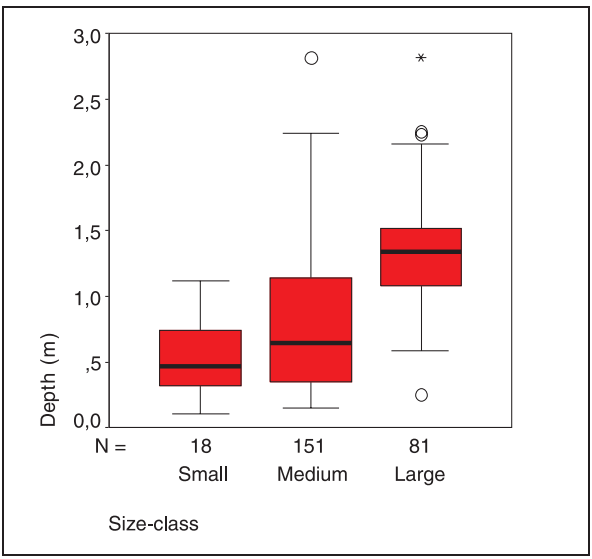

Figure 2. - Comparison for habitat use of depth $(\mathrm{m})$ between the three size classes of Barbus bocagei, through box and whiskers plots. havior was not so apparent for large $\left(\mathrm{N}=81 / \mathrm{r}^{2}=0.05\right)$ and medium-size fishes $\left(N=151 / r^{2}=0.16\right)$ as it was for small ones $\left(\mathrm{N}=18 / \mathrm{r}^{2}=0.66\right)$, so the last group had a higher correlation coefficient for the potential regression (see Figure 4).

Because depth is positively related with velocity (in theory), data could indicate that they prefer to stay closer to the bottom as velocity increases. This explanation seems logical and coherent with their swimming capabilities, because the small fishes are the more limited in terms of water velocity.

However, that relation between variables does not exist in these rivers. On the contrary, when we have done a plot of depth with average and focal velocity, one can see that as depth increases both velocities decrease (Figure 5). These hydraulic conditions are natural in many

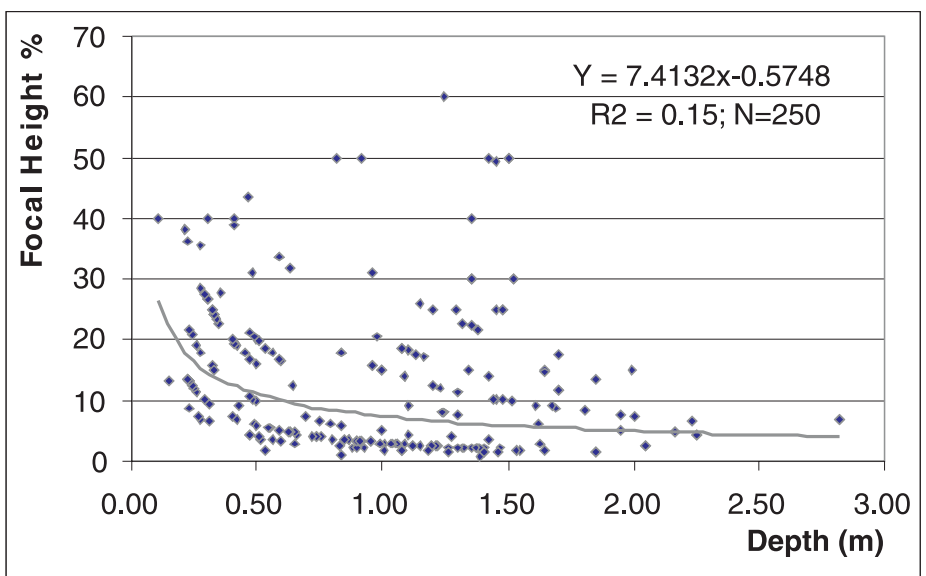

Figure 3. - Potential regression showing a relationship between focal height (in \%) and depth: global results of the 3 size classes together. Sample size $=250$. 

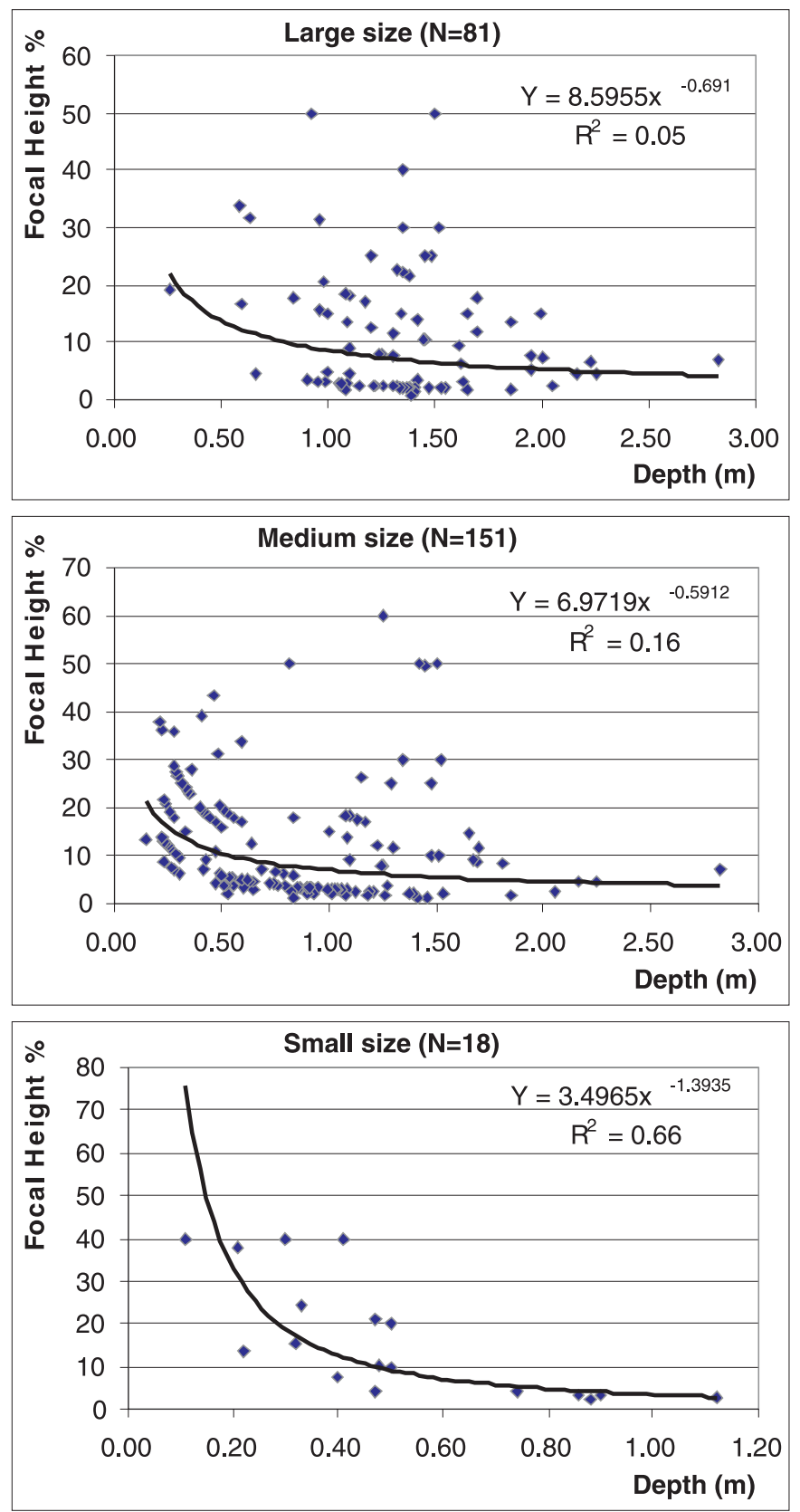

Figure 4. - Relationship between percentage of focal height and depth, for each size class of Barbus bocagei, analyzed through potential regression. 


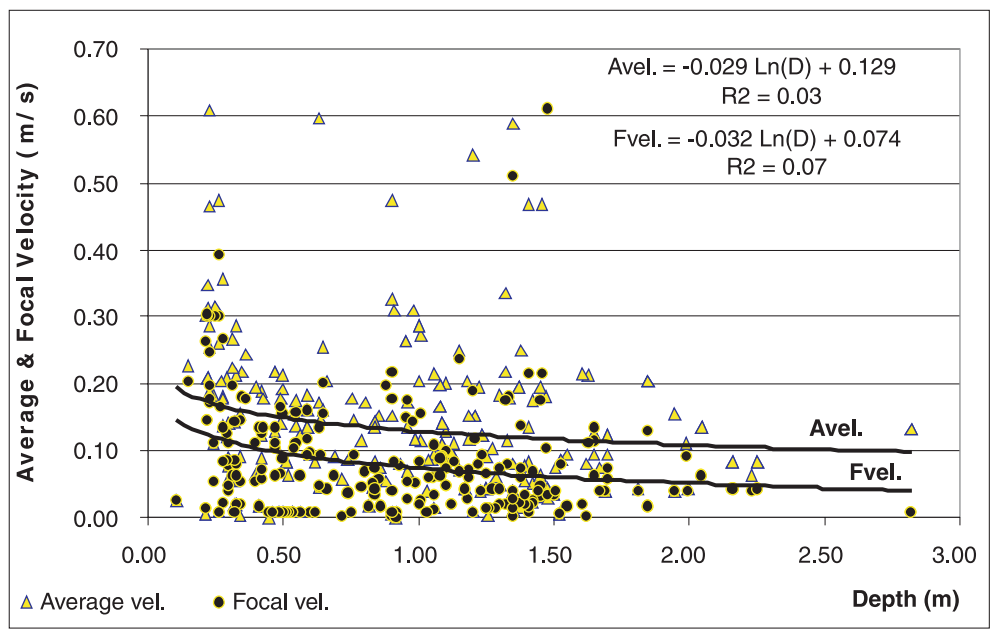

Figure 5. - Relationship of average (Avel.) and focal (Fvel.) velocity $(\mathrm{m} / \mathrm{s})$ with depth $(\mathrm{m})$, obtained through logarithmic regression, from the data recorded in the four streams.

reaches, where habitat heterogeneity and the pool-riffle structure make the river very different to an artificial channel.

When each site is treated individually, the correlation coefficients are variable. For average velocity, based on the logarithmic regression, $\mathrm{R}^{2}$ are ranging from 0.00 (Guadiela, $\mathrm{N}=100$, no relationship) to 0.21 (Sorbe, $\mathrm{N}=42$ ), but there is always a negative gradient for the trend line. In the case of focal velocity, the maximum $r^{2}$ is 0.38 (Sorbe).

In our opinion, with a general perspective (for the 3 size classes), a better interpretation of the results would be related to their need of refuge and food: when the water column is higher, they prefer to be secure near to the shelter and the food supplied by the stream bed.

\section{Estimation of focal velocities}

In our second objective, we first planned to check how is the correlation between focal and average velocity in global terms, i.e., for all the data records together (from the 4 sites). We have observed a high variation in the data (illustrated in the Figure 6), so the regression coefficient is low for the power equation (0.442).

Then we focused on the different models. First we computed the regression analysis for the first model (power regression), and the coefficients obtained were the following:

- River Ambroz: a=2.174, b=0.632;

- River Guadiela: $a=1.308, b=0.396$;

- River Jarama: a=3.188, b=0.922;

- River Sorbe: $a=1.189, b=0.422$. 


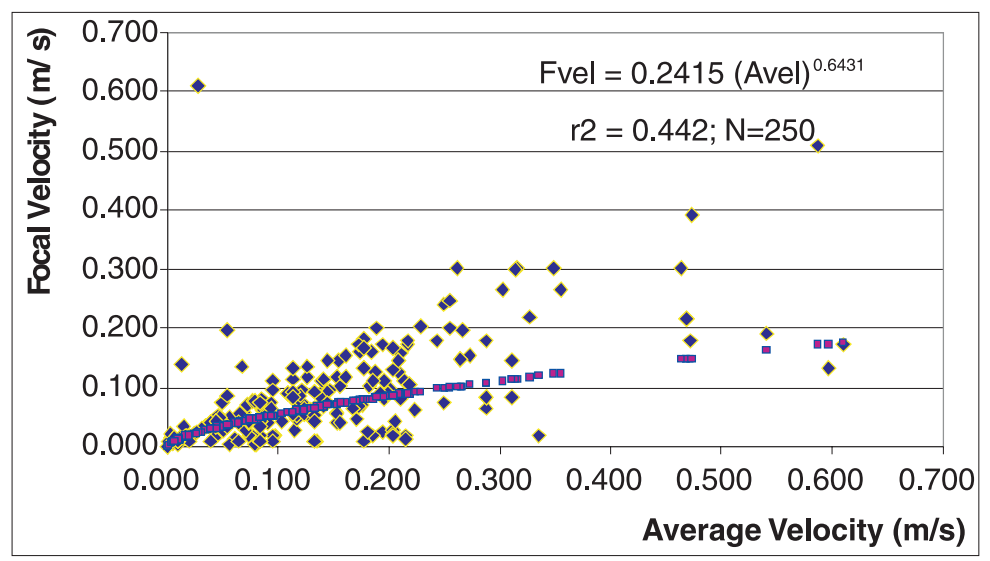

Figure 6. - Power regression for focal velocity $(\mathrm{m} / \mathrm{s})$ and average velocity $(\mathrm{m} / \mathrm{s})$ : global results of the 3 size classes of Barbus bocagei together (sample size $=250$ ).

Then we calculated the focal velocity and the error for every measurement through the 4 models. In Table 3 we have shown the percentage of points whose error is in the range of the specified intervals (detail) and also the same results in a simplified format, after combining some intervals together. For every reach we have indicated the fixed focal height, necessary for the second model, and the average of the constant $m$ for the third model. Approximately a $15 \%$ of the data were discarded in order to obtain a better fit for the empirical models, so the sample sizes were 68 for Ambroz, 87 for Guadiela, 25 for Jarama and 30 for Sorbe River. Total sample size for the analysis was 210 . For every site we have selected the best model, considering the maximum percentage of data with errors in the lowest interval, i.e., from 0 to $25 \%$. In a second place we have con- sidered the percentage of data in the other intervals.

For the River Ambroz, more than a half points have errors lower than $25 \%$ when using the empirical procedure of the second model (fixed focal height, $0.06 \mathrm{~m}$ ). The four models have in common that approximately a $91 \%$ of the data have errors lower than $100 \%$. In this reach, the calculations involved focal heights between 0.02 and $0.46 \mathrm{~m}$ (from $2 \%$ to $50 \%$ of focal height), with an average of $0.06 \pm 0.01 \mathrm{~m}$, which is down the characteristic roughness height of the site (estimated through the D65), which is $0.16 \mathrm{~m}$. Therefore, the fish selection could be notably influenced by the pocket waters and substrate shelters that provide low velocity spots near to faster currents. In fact, many fishes were observed while they were feeding between the cobbles of the stream bed. 
Table 3. - Percentages of data in every interval of error, computed when the 4 models were used to calculate focal velocity $(\mathrm{m} / \mathrm{s})$ from average velocity $(\mathrm{m} / \mathrm{s})$. Bold numbers are the percentage of points with errors between $0-25 \%$, for the best model.

\begin{tabular}{|c|c|c|c|c|c|}
\hline \multirow[b]{2}{*}{$\begin{array}{c}\text { River (sample } \\
\text { size) }\end{array}$} & \multirow{2}{*}{$\begin{array}{c}\text { Models } \rightarrow \\
\begin{array}{c}\text { Error } \\
\text { intervals }\end{array}\end{array}$} & \multicolumn{3}{|c|}{ Power Law } & \multirow{2}{*}{$\begin{array}{l}\text { Logarithmic } \\
\text { Logarithmic }\end{array}$} \\
\hline & & Empirical & $\begin{array}{c}\text { Empirical } \\
\mathrm{Fh}=0.06\end{array}$ & $\begin{array}{c}\text { Empirical } \\
m=0.405\end{array}$ & \\
\hline \multirow{10}{*}{$\begin{array}{c}\text { AMBROZ } \\
(\mathrm{N}=68)\end{array}$} & $<10 \%$ & 19 & 25 & 26 & 24 \\
\hline & $10-25 \%$ & 21 & 26 & 23 & 22 \\
\hline & $25-50 \%$ & 41 & 26 & 33 & 26 \\
\hline & $50-75 \%$ & 10 & 13 & 8 & 9 \\
\hline & $75-100 \%$ & 0 & 0 & 3 & 10 \\
\hline & $>100 \%$ & 9 & 9 & 8 & 9 \\
\hline & $<25 \%$ & 40 & 51 & 48 & 46 \\
\hline & $25-100 \%$ & 51 & 40 & 44 & 46 \\
\hline & $>100 \%$ & 9 & 9 & 8 & 9 \\
\hline & \begin{tabular}{|l} 
Error \\
intervals
\end{tabular} & Empirical & $\begin{array}{c}\text { Empirical } \\
\mathrm{Fh}=0.15\end{array}$ & $\begin{array}{c}\text { Empirical } \\
m=0.358\end{array}$ & Logarithmic \\
\hline \multirow{10}{*}{$\begin{array}{l}\text { GUADIELA } \\
(\mathrm{N}=87)\end{array}$} & $<10 \%$ & 15 & 10 & 17 & 22 \\
\hline & $10-25 \%$ & 16 & 14 & 15 & 20 \\
\hline & $25-50 \%$ & 32 & 34 & 27 & 24 \\
\hline & $50-75 \%$ & 20 & 21 & 20 & 1 \\
\hline & $75-100 \%$ & 2 & 0 & 3 & 6 \\
\hline & $>100 \%$ & 15 & 21 & 17 & 28 \\
\hline & $<25 \%$ & 31 & 24 & 33 & 41 \\
\hline & $25-100 \%$ & 54 & 55 & 50 & 31 \\
\hline & $>100 \%$ & 15 & 21 & 17 & 28 \\
\hline & $\begin{array}{l}\text { Error } \\
\text { intervals }\end{array}$ & Empirical & $\begin{array}{c}\text { Empirical } \\
\mathrm{Fh}=0.07\end{array}$ & $\begin{array}{c}\text { Empirical } \\
\mathrm{m}=0.422\end{array}$ & Logarithmic \\
\hline \multirow{10}{*}{$\begin{array}{l}\text { JARAMA } \\
(\mathrm{N}=25)\end{array}$} & $<10 \%$ & 8 & 0 & 8 & 12 \\
\hline & $10-25 \%$ & 16 & 16 & 16 & 40 \\
\hline & $25-50 \%$ & 40 & 36 & 44 & 20 \\
\hline & $50-75 \%$ & 24 & 24 & 8 & 4 \\
\hline & $75-100 \%$ & 0 & 0 & 0 & 0 \\
\hline & $>100 \%$ & 12 & 24 & 24 & 24 \\
\hline & $<25 \%$ & 24 & 16 & 24 & 52 \\
\hline & $25-100 \%$ & 64 & 60 & 52 & 24 \\
\hline & $>100 \%$ & 12 & 24 & 24 & 24 \\
\hline & $\begin{array}{l}\text { Error } \\
\text { intervals }\end{array}$ & Empirical & $\begin{array}{c}\text { Empirical } \\
\mathrm{Fh}=0.15\end{array}$ & $\begin{array}{c}\text { Empirical } \\
\mathrm{m}=0.546\end{array}$ & Logarithmic \\
\hline \multirow{9}{*}{$\begin{array}{l}\text { SORBE } \\
(\mathrm{N}=30)\end{array}$} & $<10 \%$ & 10 & 7 & 0 & 13 \\
\hline & $10-25 \%$ & 23 & 20 & 40 & 30 \\
\hline & $25-50 \%$ & 40 & 37 & 30 & 23 \\
\hline & $50-75 \%$ & 13 & 17 & 17 & 3 \\
\hline & $75-100 \%$ & 7 & 10 & 7 & 7 \\
\hline & $>100 \%$ & 7 & 10 & 7 & 23 \\
\hline & $<25 \%$ & 33 & 27 & 40 & 43 \\
\hline & $25-100 \%$ & 60 & 63 & 53 & 33 \\
\hline & $>100 \%$ & 7 & 10 & 7 & 23 \\
\hline
\end{tabular}


In the River Guadiela, the logarithmic model gave us the best results, though the percentage of errors is high in all the cases. In comparison with the River Ambroz, the percentage of data with errors over $100 \%$ is considerably higher (from 12 to $28 \%$ ), which could be related to its notable habitat heterogeneity (vegetated islands, undercut banks, etc.). In this reach the focal heights varied from 0.02 to $0.75 \mathrm{~m} \mathrm{(1 \%} \mathrm{to} 60 \%$ of focal height), with an average of $0.15 \pm$ $0.04 \mathrm{~m}$, which is over the characteristic roughness height of the site, $0.04 \mathrm{~m}$.

Similar results were observed in the River Jarama, where percentages of errors over $100 \%$ get to $24 \%$. The logarithmic model gave also the best fit, and more than a half points had errors smaller than $25 \%$. The range for the focal heights (and so the consequent calculations) was from 0.01 to $0.20 \mathrm{~m} \mathrm{(2 \%} \mathrm{to} 43 \%$ of focal height), with an average of $0.07 \pm 0.02 \mathrm{~m}$, which is lower than the substrate D65 of the site, $0.16 \mathrm{~m}$. As occurring in River Ambroz, the positions selected by the fishes could be very influenced by the substrate, and also by the undercut banks where many fishes like to stay.

Finally, in the River Sorbe, the empirical model with a fixed $\mathrm{m}$, and the logarithmic model gave the best results. Both have high percentages of errors lower than $25 \%$, but the first of them has the lowest percentage of errors over $100 \%$. Theses calculations are related to focal heights from 0.01 to $0.30 \mathrm{~m}$ ( $1 \%$ to $34 \%$ of focal height), with an average of $0.15 \pm 0.02 \mathrm{~m}$, which is lower than the substrate D65 of the site, $0.64 \mathrm{~m}$. In general we can say that substrate size had played an important role in the positions selected by the fishes, though it depends on the different mesohabitats sampled in the reach.

When we compared the errors between the 4 models, gathering the four reaches, the Kruskal-Wallis test (with a 95\% confidence level) showed that there is not a statistically significant difference $(p=0.18)$. Treating every reach separately, we can observe the same results. The probability of the test and the medians calculated can be seen in Table 4. Therefore, we can not find any significant difference to associate with the physical characteristics of the 4 sites. Even when we only looked at the error median, we did not find a pattern of variation with the physical variables selected. In the box plots it was observed that the errors (in all models) had a trend to increase with available depth and hydraulic radius, but it was a visual effect of some extreme data (outliers) with a little statistical value.

In regards to the microhabitat variables that describe the habitat use by the barbel, we have found that, as focal velocity increases, the errors go down, and the same happen with the focal height (in the four models). When we analyzed the relationship between focal height and focal velocity, we have seen that the fish selected high positions in the water column only when they could find low focal velocities in those positions. Since average 
Table 4. - Medians of the errors for each study site and probability of the Kruskal-Wallis test $(\alpha=0.05)$ that compares the errors of the four models used to estimate nose velocities (median test).

\begin{tabular}{|l|c|c|c|c|}
\hline River name & Power Law & & Logarithmic \\
\hline $\begin{array}{l}\text { AMBROZ } \\
\text { (N=68) }\end{array}$ & Empirical & $\begin{array}{c}\text { Empirical } \\
\text { Fh=0.06 }\end{array}$ & $\begin{array}{c}\text { Empirical } \\
\text { m=0.405 }\end{array}$ & Logarithmic \\
\hline $\begin{array}{l}\text { Error Median } \\
\text { Kruskal-Wallis } p\end{array}$ & 49 & 58 & 54 & 66 \\
\hline $\begin{array}{l}\text { GUADIELA } \\
\text { (N=87) }\end{array}$ & Empirical & $\begin{array}{c}\text { Empirical } \\
\text { Fh=0.15 }\end{array}$ & $\begin{array}{c}\text { Empirical } \\
\text { m=0.358 }\end{array}$ & Logarithmic \\
\hline $\begin{array}{l}\text { Error Median } \\
\text { Kruskal-Wallis } p\end{array}$ & 86 & 111 & 98 & 147 \\
\hline $\begin{array}{l}\text { JARAMA } \\
\text { (N=25) }\end{array}$ & Empirical & $\begin{array}{c}\text { Empirical } \\
\text { Fh=0.07 }\end{array}$ & $\begin{array}{c}\text { Empirical } \\
\text { m=0.422 }\end{array}$ & Logarithmic \\
\hline $\begin{array}{l}\text { Error Median } \\
\text { Kruskal-Wallis } p\end{array}$ & 72 & 108 & 100 & 115 \\
\cline { 2 - 6 } $\begin{array}{l}\text { SORBE } \\
\text { (N=30) }\end{array}$ & Empirical & $\begin{array}{c}\text { Empirical } \\
\text { Fh=0.15 }\end{array}$ & $\begin{array}{c}\text { Empirical } \\
\text { m=0.546 }\end{array}$ & Logarithmic \\
\hline $\begin{array}{l}\text { Error Median } \\
\text { Kruskal-Wallis } p\end{array}$ & 59 & 60 & 60 & 90 \\
\cline { 2 - 6 } & \multicolumn{5}{|c|}{0.57} \\
\hline
\end{tabular}

velocity is correlated with the focal velocity, we have also observed that the errors reduce when this variable goes up, but the trend is not so clear as it is for the focal velocity.

If we would decide based in the medians only, Guadiela would be the reach with highest errors and Ambroz would be the opposite. From this point of view, the worst situation to model focal velocity is the empirical model, with focal height $0.15 \mathrm{~m}$, in the River Guadiela. The best model would be the empirical (focal height variable) in the River Ambroz.

\section{Physical Habitat Simulation}

For the third part of this article, we selected a reach for a habitat simula- tion, the River Sorbe. Their data were complete for a habitat simulation and the reach had several habitat units, with alternating pools and riffles. It was characterized by high habitat heterogeneity. We calculated focal velocities by the third model calculated for Sorbe, i.e., the empirical model with a constant $m=0.546$. We also introduced a constant focal height for the simulation: the median for large barbel $(\mathrm{N}=22)$ in the River Sorbe, $0.16 \mathrm{~m}$. Finally this is the formula we used:

$$
\text { Fvel }=\text { Avel } \cdot 1.546(0.16 / D)^{0.546}
$$

Table 5 shows the habitat criteria introduced into the WUA simulation. Since the calculated optimal and suitable focal heights are lower than the 
Table 5. - Habitat suitability criteria for Barbus bocagei calculated from 81 records from the rivers Ambroz, Guadiela, Jarama and Sorbe, which have been used in the physical habitat simulation. The variables implemented are total depth $(\mathrm{m})$, average velocity $(\mathrm{m} / \mathrm{s})$ and focal velocity $(\mathrm{m} / \mathrm{s})$.

\begin{tabular}{|c|c|c|c|c|}
\hline \multirow{2}{*}{$\begin{array}{c}\text { Large Barbel } \\
(\mathrm{N}=81)\end{array}$} & Interval & Depth & Average Velocity & Focal Velocity \\
\cline { 2 - 5 } & Suitable & $0.6-2.23$ & $0.01-0.541$ & $0.005-0.215$ \\
\cline { 2 - 5 } & Optimal & $1.09-1.52$ & $0.069-0.194$ & $0.032-0.097$ \\
\hline
\end{tabular}

minimum depth suitable for large barbel $(0.6 \mathrm{~m})$, we have considered that we do not need to introduce habitat criteria for focal heights in the simulation, in this particular case. Therefore, total depth combined with average or with focal velocity have been considered to calculate the weighted usable area in two ways. The range of simulated flows was from 0.5 to $5.0 \mathrm{~m}^{3} / \mathrm{s}$, with 0.5 intervals, plus the calibration flow $\left(2.23 \mathrm{~m}^{3} / \mathrm{s}\right)$. The simulation was based on 10 transects.

The results are summarized (in form of table and curves) in Figure 7 (weighted usable area in $\mathrm{m}^{2}$, versus discharge). This figure shows how different are the two procedures followed. In a wide range of instream flows, the WUA $\left(\mathrm{m}^{2}\right)$ obtained differ in percentages from positive $21 \%$ to negative (most cases) $37 \%$ (for $3.5 \mathrm{~m}^{3} / \mathrm{s}$ ). In this cases the percentages were calculated as the difference $\operatorname{WUA}(A)-W \cup A(B)$ divided by $\operatorname{WUA}(A)$, i.e., in relation to the usual method. In general we could say that the common procedure, based on average velocities, is underestimating the real WUA for this species in this site.
In regards to the habitat conditions, the D65 for the reach was 0.64 , so we could expect a relevant influence of the characteristic roughness on the fish behavior and their position in the water column. We also must remember the limitations for the focal velocity model, with a $40 \%$ of errors between 0 and $25 \%$, and a $53 \%$ of associated errors in the range of 25$100 \%$ (based on our empirical data for this study site).

\section{DISCUSSION}

The first part of this article describes how Barbus bocagei select low positions in the water column. Barbels are typically epi-benthic fishes that spawn in gravel beds (Doadrio 1984; Lobón-Cerviá \& De Diego 1988; Doadrio et al. 1991; Baras 1994) and our observations have confirmed their vital association with the river bed. Former authors have observed the same behavior by underwater surveys in Iberian rivers (Grossman et al. 1987a \& b; Grossman \& De Sostoa 1994a \& b). Barbels are present in many European rivers, where frequently they 


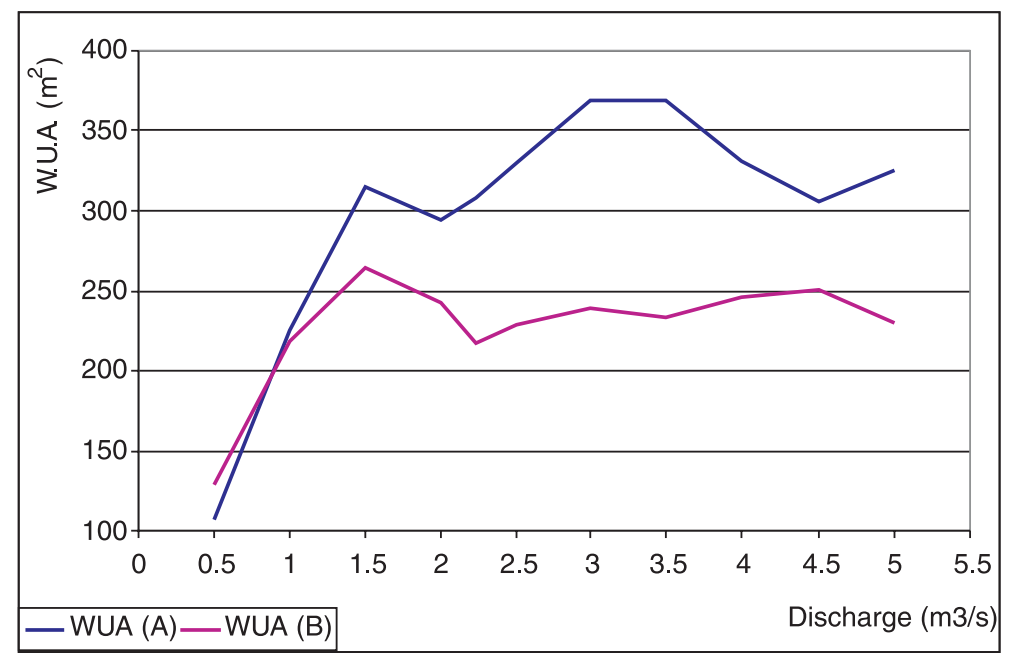

Figure 7. - Weighted usable area $\left(\mathrm{m}^{2}\right)$ for adult barbel simulated in the Sorbe River. WUA has been calculated for each flow, with two different habitat suitability criteria: depth $(\mathrm{m})$ with average velocity $\left(\mathrm{m}^{3} / \mathrm{s}\right)$, method $A$, or depth $(\mathrm{m})$ with focal velocity $\left(\mathrm{m}^{3} / \mathrm{s}\right)$, method $B$.

have more than a $50 \%$ of the community biomass and play a principal ecological role (Philippart \& Baras 1996). This is a reason why we consider important their study and the improvement of the habitat simulations where they inhabit.

In regards to depth, we have observed that the larger individuals usually occupy deeper microhabitats, what have been demonstrated for barbels and different European cyprinids (Grossman et al. 1987 a,b; Copp 1990, 1992; Grossman and De Sostoa 1994 a,b; Prenda 1993; Lamouroux et al. 1999).

The use of four models to calculate focal velocities gave us unexpected results. At the first sight, when the errors were classified into intervals, they seemed to be very different. After comparing the medians by the Kruskal-Wallis test (all together and for every site separately) we discovered that there were no significant differences between them. We have not known this kind of comparison before, because Milhous (1999) compared the errors by intervals. We just can say that the models do not give different results in statistical and practical terms. In general, Milhous obtained that the models could give errors lower than $30 \%$ in more than half measurements. In this research the intervals were different, considering an acceptable error under $25 \%$. The number of acceptable errors varied much between reaches, but only in a few cases they were more than half cases. 
In our opinion, habitat characteristics like characteristic roughness, mean annual flow, etc. can cause the different results in relation with Lower Cataract Creek and Salmon River (see Milhous 1999). A basic difference is also in the methods because, in our field work, average and focal velocity were measured at the same point, one immediately after the other, by the same person. We consider our four study sites are very different (and the focal heights where errors were evaluated), in the range of Iberian rivers with order 3-4 (Strahler 1957), so our results could be valid for a large number of river reaches.

Our work confirm with Milhous (1999) that focal velocities simulations are possible and practical, and that their implementation into the actual simulation systems can be very important in the estimations of weighted usable area, for several species and in different conditions (not only in the spawning period). Better models for the velocity prediction are also an important challenge. In current works for minimum flow assessments we recommend to follow similar procedures for a reach: study or validations of habitat criteria, for every species (either benthic or not), comparison of several models to compute focal velocities (evaluating errors for a random sample, in the focal height selected by a species), and application of the best model (if it does exist and it is good enough) in the physical habitat simulation.

\section{SUMMARY}

We have obtained habitat suitability criteria for small, medium and large size barbels, in several rivers of the Tagus Basin. The results show that the fish usually stay in low positions in the water columns, i.e., percentages of focal height (distance from the bottom/depth) from 8 to $12 \%$. Data analysis has showed that large fish occupy deeper microhabitats and a wider range of positions in the water column. As depth increases, the barbels prefer to stay closer to the bottom. In terms of velocity, they stay higher in the water column when the focal velocity is low, but they keep nearer to the bottom when the focal velocity is high.

The four models used to calculate focal velocities offer dissimilar accuracies in the reaches studied. The lowest errors corresponded to the rivers Ambroz and Jarama, where a model (empirical and logarithmic, respectively) gave more than a $50 \%$ of errors minor than $25 \%$. The errors obtained do not show a clear pattern in relation to their habitat characteristics. Those errors are clearly and negatively related to the focal velocity, focal height and average velocity in the microhabitats selected by the fish.

The implementation of habitat suitability criteria for focal velocities is an important approach to improve the actual habitat simulations. In the case of benthic species, like Barbus sp., the weighted usable area is expected to vary in a significant scale, as can 
be seen in the habitat simulation for the River Sorbe.

\section{ACKNOWLEDGMENTS}

The assistance of Ester Naveiro, Juan Diego Alcaraz and other colleagues has been essential for the completion of this research: Marta Morillo, Amador Jiménez, Bárbara Gutiérrez, Charo Sendín, $M^{\mathrm{a}}$ Jesús Montenegro, $\mathrm{M}^{\mathrm{a}}$ Mar Domínguez, Julio Lurueña, Ezequiel Rodríguez and Carlos Alonso. This research project has been supported by the Spanish authorities for Science and Technology (Project AMB 95-0914).

\section{REFERENCES}

Baeza, D., F. Martínez-Capel, D. García de Jalón 2001. Análisis de los efectos reguladores de las presas en la variabilidad de caudales en los ríos. Pages: 333-344. In: Avances en Ingeniería Ambiental. Cartagena, Spain: Universidad Politécnica de Cartagena. ISBN: 84-95781-02-6.

Baras, E. 1996. Selection of residence area and non-reproductive homing in a shoaling freshwater teleost, the barbel Barbus barbus (L). Pages: 47-58. In: Underwater Biotelemetry, Proccedings of the $1^{\text {st }}$ Conference and Workshop on Fish Telemetry in Europe. E. Baras \& J.C. Philippart, (Eds.). University of Liege. Belgium.

Bovee, K.D. 1982. A guide to stream habitat analysis using the instream flow incremental methodology. United States Fish and Wildlife Service, Cooperative Instream Flow Group, Instream Flow
Information Paper $\mathrm{n}^{\circ}$ 12. Fort Collins, Colorado, USA.

Bovee, K.D. 1986. Development and evaluation of habitat suitability criteria for use in the Instream Flow Incremental Methodology. Instream Flow Information Paper $n^{\circ} 21$. United States Fish and Wildlife Service. Biol. Rep. 86 (7). Fort Collins, Colorado, USA.

Copp, G.H. 1990. Shifts in the microhabitat of larval and juvenile roach Rutilus rutilus(L.) in a floodplain channel. Journal of Fish Biology, 36: 683-692.

Copp, G.H. 1992. Comparative microhabitat use of cyprinid larvae and juveniles in a lotic floodplain channel. Environmental Biology of Fishes, 33: 181-193.

Doadrio, I. 1984. Relaciones filogenéticas y biogeográficas de los barbos (Barbus, Cyprinidae) de la Península Ibérica y aportes corológicos y biogeográficos a su ictiofauna continental. Doctoral Thesis. Madrid, Spain: Universidad Complutense de Madrid.

Doadrio, I., B. Elvira, Y. Bernat 1991. Peces continentales españoles. Inventario y clasificación de zonas fluviales. ICONA, Colección Técnica. M.A.P.A. I.C.O.N.A.-C.S.I.C. Spain.

Dolloff, C.A., D.G. Hankin, G.H. Reeves 1993. Basinwide estimation of habitat and fish populations in streams. General Technical Report SE-83. U.S. Forest Service, washington, DC., USA.

García de Jalón, D. 1987. River regulation in Spain. Regulated Rivers : Research and Management, 1: 343-348.

García de Jalón, D., B. Gutiérrez, F. Martínez-Capel, M. Morillo, S. Baselga, D. Baeza 1997. Realización de la metodología de cálculo de aportaciones ambientales y caudales ecológicos mínimos en la cuenca hidrográfica del río Tajo. Technical report for CEDEX. Madrid, Spain.

Granado-Lorencio, C. 1996. Ecología de peces. Seville, Spain: University of Seville. 
Grossman, G.D., A. De Sostoa, M.C. Freeman, J. Lobón-Cerviá 1987a. Microhabitat use in a mediterranean riverine fish assemblage: I. Fishes of the lower Matarraña. Oecologia, 73: 490500.

Grossman, G.D., A. De Sostoa, M.C. Freeman, J. Lobón-Cerviá 1987b. Microhabitat use in a Mediterranean riverine fish assemblage: II. Fishes of the upper Matarrana. Oecologia, 73: 501512.

Grossman, G.D., A. De Sostoa 1994a. Microhabitat use by fishes in the lower rio Matarraña, Spain: 1984-1987. Ecology of Freshwater Fish, 3: 123-136.

Grossman, G.D., A. De Sostoa 1994b. Microhabitat use by fishes in the upper rio Matarraña, Spain: 1984-1987. Ecology of Freshwater Fish, 3: 141-152.

Hankin, D.G., G.H. Reeves 1988. Estimating total fish abundance and total habitat area in small streams based on visual estimation methods. Can. J. Fish. Aquat. Sci., 41: 1575-1591.

Heggenes, J. 1991. Comparisons of habitat availability and habitat use by an allopatric cohort of juvenile Atlantic Salmon (Salmo salar) under conditions of low competition in a Norwegian stream. Holarct. Ecol., 14: 51-62.

Jowett, I. G. 1989. River hydraulic and habitat simulation, RHYHABSIM computer manual. New Zealand fisheries miscellaneous report 49. Ministry of Agriculture and Fisheries. Christchurch, New Zealand.

Lamouroux, N., H. Capra, M. Pouilly, Y. Souchon 1999. Fish habitat preferences in large streams of southern France. Freswater Biology, 42: 673687.

Li, S.K. 1988. Measuring microhabitat in swift water. Pages: 183-193 in K.D.Bovee y J.R. Zuboy, (Eds.) Proceedings of a workshop on the development and evaluation of habitat suitability criteria. U. S. Fish and Wildlife Service Biological Report 88 (11).
U.S. Fish and Wildlife Service. Washington, DC., USA

Lobón-Cerviá, J., C. Fernández Delgado 1984. On the biology of the barbel (Barbus barbus bocagel) in the Jarama River. Folia Zoológica, 33(4): 371-384.

Lobón-Cerviá, J., A. De Diego 1988. Feeding strategy of the barbel (Barbus bocagei Steindachner) with relation to benthos composition. Archives für $\mathrm{Hy}$ drobiologie, 114(1): 83-95.

Martínez-Capel, F., D. García de Jalón 1999. Desarrollo de curvas de preferencia de microhábitat para Leuciscus pyrenaicus y Barbus bocagei por buceo en el río Jarama (Cuenca del Tajo). Limnetica, 17: 71-83.

Martínez-Capel, F. 2000. Preferencias de microhábitat de Barbus bocagei, Chondrostoma polylepis y Leuciscus pyrenaicus en la cuenca del río Tajo. Microhabitat preferentes of Barbus bocagei, Chondrostoma polylepis and Leuciscus pyrenaicus in the Tagus basin (Spain). Doctoral Thesis. Madrid, Spain: Universidad Politécnica de Madrid.

Martínez-Capel, F., F. Hervella, M. Sainz de los Terreros, D. García de Jalón 2000. Assessing impacts of a hydropower plant: Ebro River, Spain. Hungarian Journal of Industrial Chemistry, 2: 1-6.

Milhous, R.T. 1999. Nose velocities in physical habitat simulation. In: Hydraulic Engineering for Sustainable Water Resources Management at the turn of the Millenium. Proceedings of the XXVIII IAHR Congress. Technical University Graz, Institute for Hydraulics and Hydrology. Graz, Austria.

Philippart, J.C., E. Baras 1996. Comparison of tagging and tracking studies to estimate mobility patterns and home range in Barbus barbus. Pages: 3-12 in E. Baras y J.C. Philippart (Eds.) Underwater biotelemetry, Proccedings of the 1st Conference and Workshop on Fish 
Telemetry in Europe. University of Liege. Bélgica.

Prenda, J. 1993. Uso del hábitat en algunas poblaciones de animales acuáticos de un río del sur de España. Influencia de las interacciones bióticas. Doctoral Thesis. Seville, Spain: University of Seville.
Strahler, A.N. 1957. Quantitative analysis of watershed geomorphology. Transactions of the American Geophysical Union, 36: 913-920.

Valladolid, M., M. Przybylski 1996. Feeding relations among cyprinids in the Lozoya river (Madrid, Central Spain). Polskie Archiwum Hydrobiologii, 43: 213-223. 
